\section{EMBRYAIDDLE Aeronautical University}

SCHOLARLY COMMONS

\section{International Journal of Aviation,} Aeronautics, and Aerospace

\title{
Literature Review: Biomimetic and Conventional Aircraft Wing Tips
}

\author{
Naseeb Ahmed Siddiqui \\ International Islamic University - Malaysia, siddiquinaseeb@gmail.com \\ Waqar Asrar \\ International Islamic University - Malaysia, waqar@iium.edu.my \\ Erwin Sulaeman \\ International Islamic University Malaysia, esulaeman@iium.edu.my
}

Follow this and additional works at: https://commons.erau.edu/ijaaa

Part of the Aerodynamics and Fluid Mechanics Commons, Aeronautical Vehicles Commons, Cosmology, Relativity, and Gravity Commons, and the Space Vehicles Commons

\section{Scholarly Commons Citation}

Siddiqui, N. A., Asrar, W., \& Sulaeman, E. (2017). Literature Review: Biomimetic and Conventional Aircraft Wing Tips. International Journal of Aviation, Aeronautics, and Aerospace, 4(2). https://doi.org/10.15394/ ijaa.2017.1172

This Literature Review is brought to you for free and open access by the Journals at Scholarly Commons. It has been accepted for inclusion in International Journal of Aviation, Aeronautics, and Aerospace by an authorized administrator of Scholarly Commons. For more information, please contact commons@erau.edu. 
The aerodynamic drag has been historically categorized into pressure drag which includes interference \& roughness drag, shock drag, skin friction drag, and drag due to lift or inviscid drag. Depending on the speed of aircraft the intensity of drag changes; in subsonic aircraft, the principal drag components are friction drag and drag due to lift. Similarly, at supersonic speed wave drag can be of the same order as drag due to lift and friction drag. Transition delay or laminar flow control (LFC) was employed to reduce the viscous drag, which was done through pressure gradients on the available swept wing, while the swept wing cross flow instability problem was relieved through suction (Bushnell \& Tuttle, 1979).

The so-called drag-due-to-lift has two important parts as per theory. First, is 'induced drag' which is a contribution of spanwise loading of the wing. This induced drag is relatively independent of wing section design and planform or Reynolds number but is a strong function of aspect ratio. The second smaller component of drag-due-to-lift is called 'form drag,' which strongly depends on Reynolds number, shape and planform of a wing but is almost independent of aspect ratio. Form drag is generated due to the wing load in the chordwise direction. For a well-designed controlled take-off and landing wing, they should be of the lowest order (Yates \& Donaldson, 1986). The generation of this induced drag depends on the spanwise vortices of the wing and especially of the wingtip area. At the end of vorticity generation, only two major counter-rotating vortices remain which are responsible for the production of downwash which results in induced drag (Anderson, 2001). It was Lanchester in 1907, who first discussed the physical model of induced drag showing vortex and downwash. According to him, induced drag can be reduced by minimizing the span loading of the wing. Then in 1918, Ludwig Prandtl proposed his lifting line theory to predict induced drag which was further expanded by his student Max Munk during 1919 by providing a closed-form mathematical expression (Anderson, 2001). As per Anderson (2001) induced drag is $25 \%$ of the total drag at cruise but can be $60 \%$ or more of the total drag at takeoff; hence NASA and the aircraft industry have taken a keen interest to reduce it.

Fredrick Lanchester in 1897 first proposed and patented the endplate wingtip device. At first, wingtip designs were related to the classical linear theory which says that increased aspect ratio, lower lift coefficient, and elliptical load distribution considering the structural limit can reduce the induced drag (Spillman, 1987; Henderson \& Holmes, 1989; Rokhsaz, 1993). 


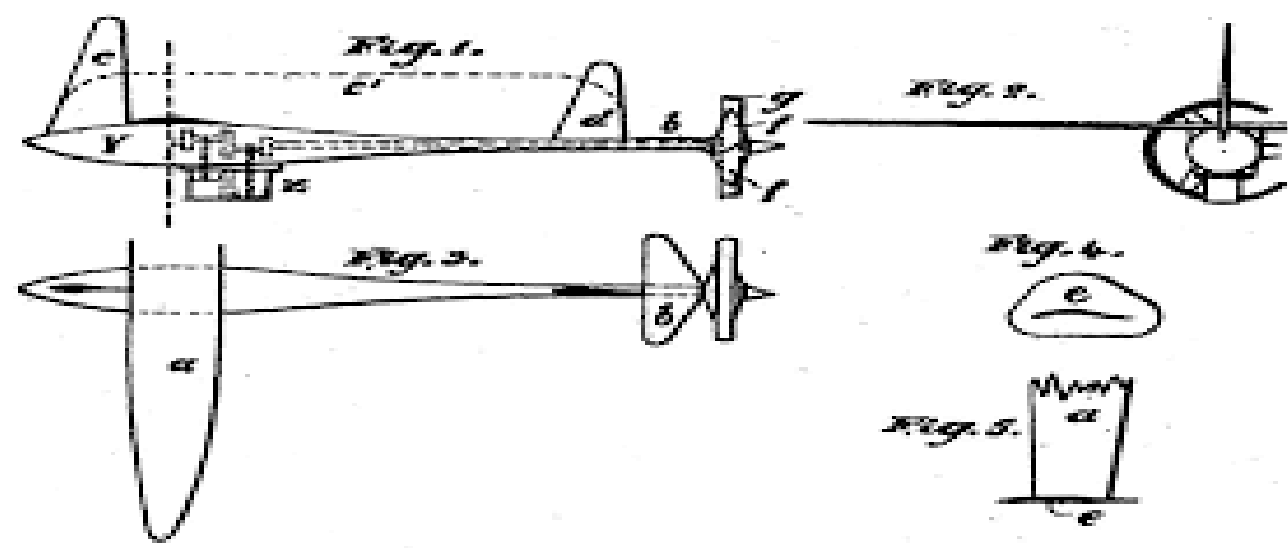

Figure 1. Proposed Aerial torpedo with End plate wingtip device by Lanchester, (Craes, 2014)

The characteristics of flying birds are such that they can change their wing shape almost instantly. They do it by extending and contracting their wing and tips of primary feathers. At the end of primary feathers, tips bend horizontally as well as vertically, providing a slotted wing planform. This is the case for the soaring birds over lands but not in the birds which soar over oceans who have pointed sharp tips. These primary feathers with slotted wingtips are thought to reduce the aerodynamic drag (Withers, 1981; Norberg, 1990). Tucker (1994) was first to check this hypothesis by experimenting on real birds. He showed that in reality, these slotted wing tips did reduce the induced drag.

\section{Reduction of Induced Drag}

Two separate studies have been performed by various researchers in the literature to reduce induced drag. In the first method, various new wing tip designs inspired by a bird's wing tip were proposed to observe the effects on the aerodynamics of an airplane. In the second method, the aerodynamics of bird's feather has been studied extensively to determine the effect of their unusual feather tip design, to check the possibility and adoption directly to real aircraft. The second method can also be classified according to the use of feathers as given below:

a. The use of feather substitutes for experiments.

b. The use of original bird feather for experiments.

This bifurcation is to ease our review according to categories just mentioned for better clarification and understanding of the history of research in this felid.

\section{Induced drag and Conventional wing tip research}


Induced drag results from the lift gained by the airplane through a natural process. According to Henderson and Holmes (1989) increased aspect ratio, elliptical loading, and low lift coefficient are the main criteria to be considered for induced drag reduction and classical linearized theory do support this stand. All these criteria have their limitations which cannot be crossed off due to valid design reasons. It is not feasible to allow an increase in aspect ratio and wing span after a certain limit due to structural and weight constraints.

The minimum induced drag for a non-planar wing was discussed by Munk (1921). Cone (1962) has provided the analytical solution of some non-planar wings. Zimmer (1987), Lyapunov (1993) and Kroo et al. (1996) argued that by considering the assumption of linear theory one can develop better ways to reduce vortex drag. The significant advancement in this direction is the development of non-planar lifting surfaces which distribute the lift vertically through various configurations like a variety of wingtip shapes. Methods have been proposed to retrieve energy in the form of thrust from the vortex drag by using some configuration like tip sails and vortex diffuser vanes other than wingtips (Degen et al., 1957; Spillman, 1978; Hackett, 1983; Webber \& Dansby, 1983; Roche \& Palffy, 1996).

Fredrick Lanchester in 1897 first proposed the endplate wingtip device. This endplate was able to reduce induced drag but was not able to reduce the overall drag. Increase in the viscous drag during cruise out-runs the reduced induced drag. Whitcomb first studied this induced drag vortex generation after his work on supercritical wings and proposed placing vertical wings between the flows to reduce the vortex generation. He and his team conducted experiments in an 8-foot transonic pressure tunnel from 1974 to 1978 and applied it on a converted KC-135 airplane three years later (NASA history series, 2012).In a separate report, Whitcomb (1976) proposed new wing tips which he called winglets to see the aerodynamic effect in practice; he found that the winglets reduced the induced drag by about $20 \%$ with an increase in wing lift-drag ratio by $9 \%$ for Mach number 0.78 and near the design lift coefficient. This improvement was twice as a comparable wingtip extension. Heyson (1977) conducted an experiment to study the advantages of Whitcomb's winglet. His results indicate that winglets would reduce the induced drag more than tip extensions and would be at its best when they are nearly vertical. Jones and Lasinski (1980) showed using Trefftz-plane theory that the vertical length of a winglet should be twice the length of a horizontal extension to have its advantages over a tip extension. 

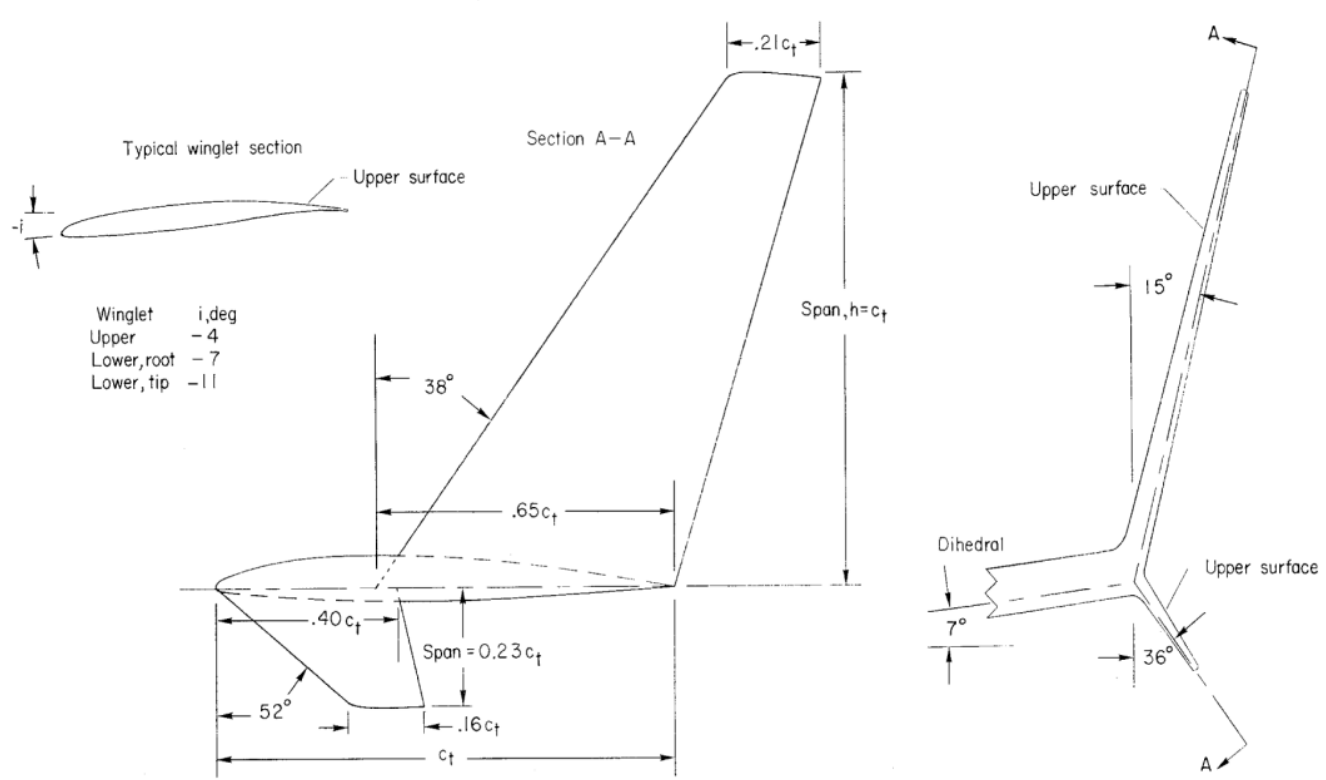

Figure 2. Winglet geometry used by Richard T. Whitcomb (1976)

Whitcomb focused on winglets for practical applications only and compared his winglet with simple wingtip extension, which would have a similar impact on the root bending moment of the wing. It can be argued that if the increase in the lift is only able to counter the weight of added structure due to winglet then is it an improvement? Even with better performance compared to wing-tip, Whitcomb realized that his design was still not optimized due to limitations of the methods used in the research (Whitcomb, 1976).

Jones and Lasinski (1980) analyzed elliptical shaped wing tips and proposed that if the limitation on planform is superseded by the structural constraint on the integrated bending at the root then according to Prandtl lifting line theory. A $10 \%$ reduction in induced drag can be achieved by a $10 \%$ increase of wing span with larger taper ratio. They found that the same result could be reached by a $15 \%$ vertical extension at the wingtip. Conley (1980) has studied the effect of toe-angle on the Learjet winglet and concluded that toe-out angle does help to fine tune and improve the performance. 


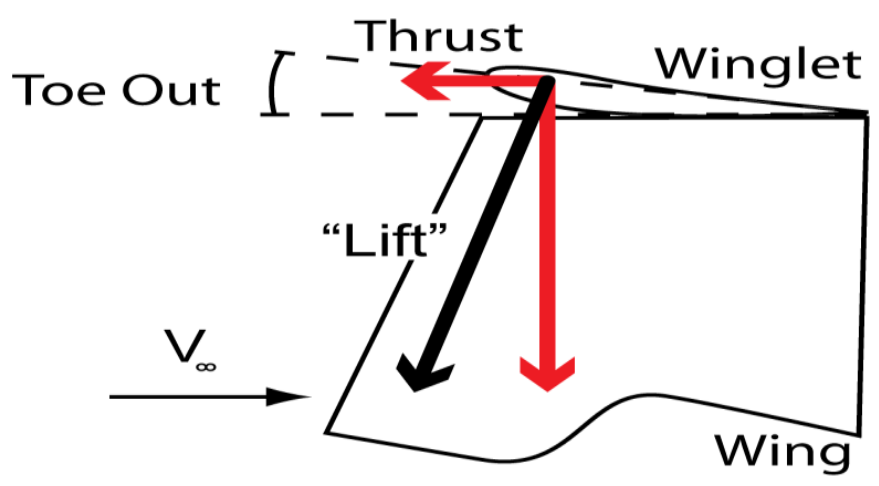

Figure 3. Effect of Toe angles (Weierman \& Jacob, 2010)

Conley (1980) noted that a winglet should be placed aft of the main wing quarter chord, so it does not superimpose the increased velocities over the inner surface of the winglet on the high velocities over the forward region of the wing upper surface. US Air Force and Boeing jointly conducted research to retrofit a Boeing KC-135A Stratotanker with removable winglets and compared wind tunnel results with actual flight data. The wind tunnel results were verified, and improvements in fuel mileage between $4.4 \%$ and $7.2 \%$ were demonstrated (Barber et al., 1981).

As per Keisuke (1985), winglets have improved performance for several reasons, and parasite drag is one of the most important reasons behind that improvement. Winglets are very narrow compared to wing-tip extensions so they would have less parasite drag. If the root bending moment and the parasite drag are kept constant, a planar wing can be designed which will be more efficient. Yates and Donaldson (1986) at NASA experimented on various configurations of available wing tip devices including a Whitcomb winglet, feather, and sail. They found that the entire tested configuration can reduce the drag by $10-15 \%$ if they are designed as an integral part of the wing. From here the idea of blended winglet was first generated. Kuhlman et al. (1988) from NASA conducted experiments on winglet and wing design of aspect ratios 1.75 and 2.67 with a taper ratio of 0.2 . The sweep angle was in the range of 45 to $60 \mathrm{deg}$. The length of winglet was fixed to $15 \%$ of the wing semi-span. Predicted pressure drag for the winglet was $15 \%$ in comparison to the wing alone at $\mathrm{M}=0.8, \mathrm{C}_{\mathrm{L}}=0.3$. The total decrease in drag coefficient was $12 \%$ compared to the wing alone case. Bending moment coefficient at wing root increased by 5-7\%. However, separate studies were made on different configurations of winglets by researchers and airplane producers depending on various patents. For example, an extensive development is patented with number US 6345790B1on the claims made by the35 U.S.C. 119 of German Patent 
Application 19926 832.0. This review does not cover such separate studies on the particular form of wingtip configurations.

Gratzer (1994) of Aviation Partners Inc. (API) developed and patented an advanced design of a winglet called blended winglet to reduce the interference drag due to sharp edges as seen in the Whitcomb's winglet. He developed spiroid-tipped wing tip device also (Gratzer, 1992).

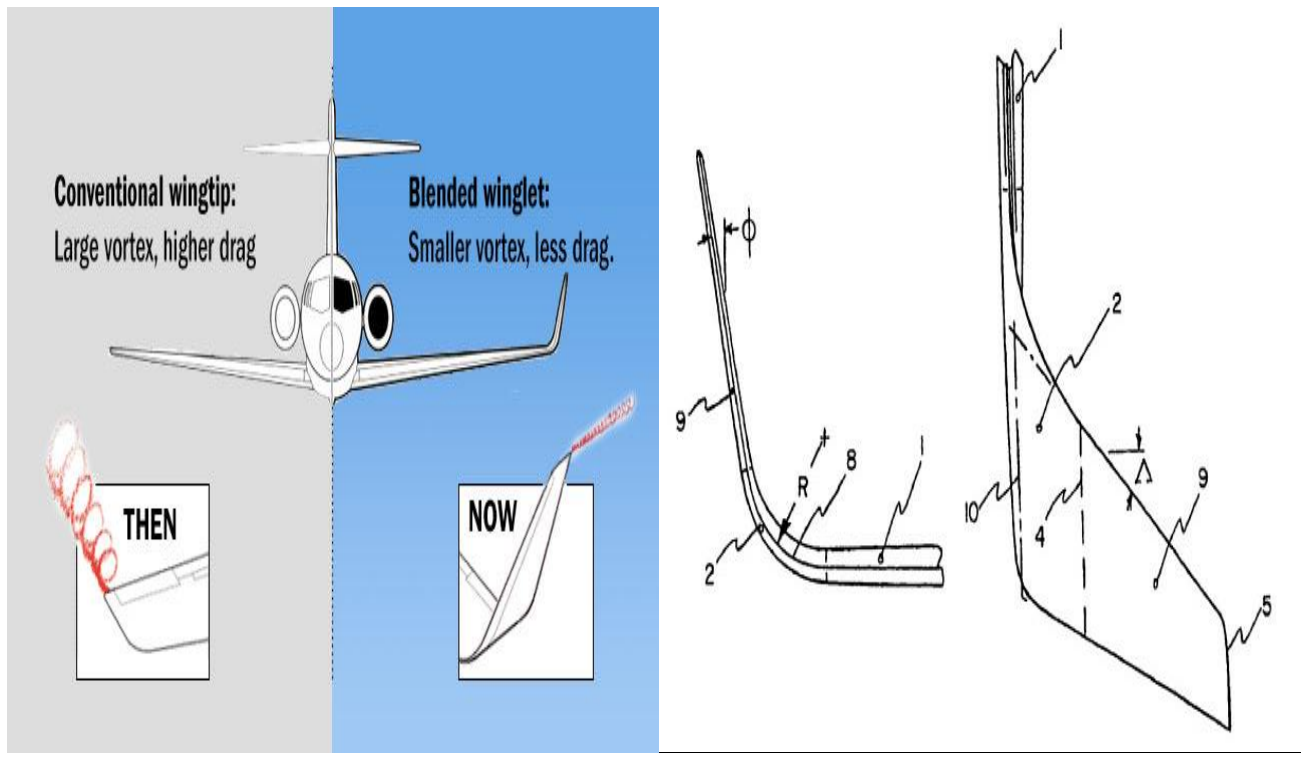

Figure 4. Blended winglet (http://www.aviationpartners.com/technology.html and (Gratzer, 1994)

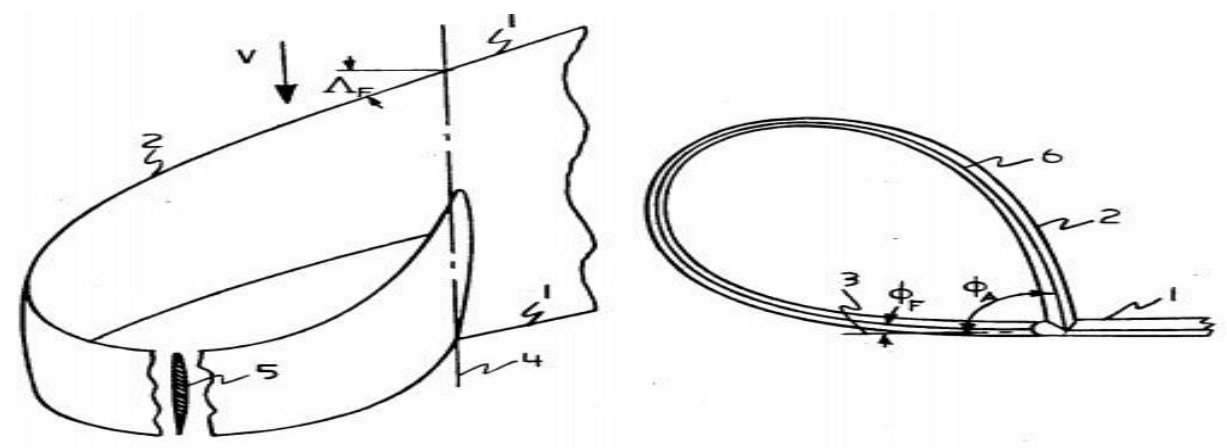

Figure 5. Spiroid wingtip, US Patent (Gratzer, 1992)

Dengbin et al. (1994) investigated three different wingtip devices namelywingtip sail, winglet and sheared wing tip. They found that all the tested tip shapes performed well and reduced induced drag at near design condition 


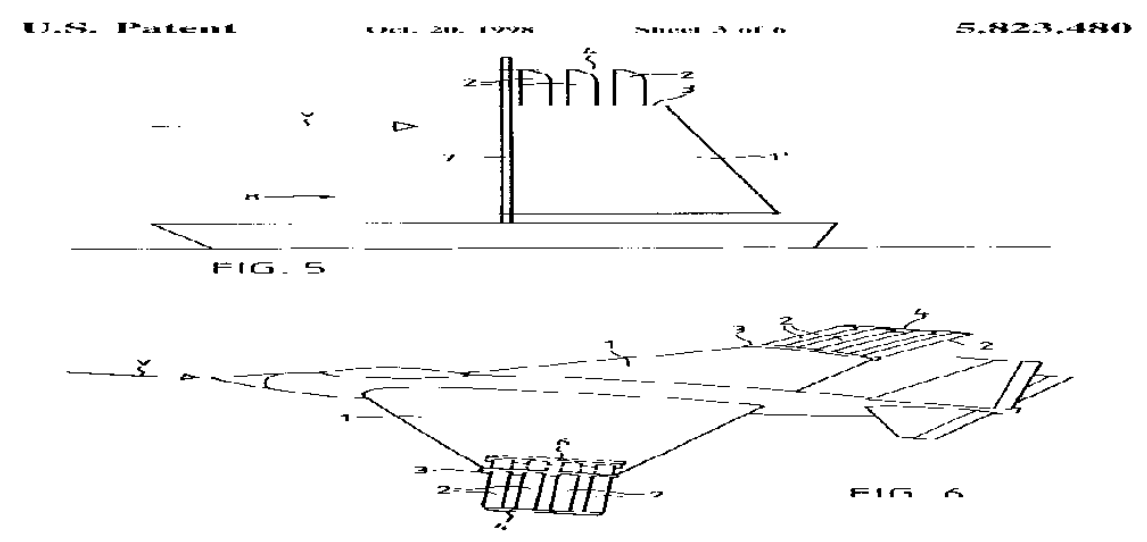

Figure 6. Wing grid wing tip (Roche, 1996)

Compared to 'Wing tip extension' of the same length but the wing tip sail is most efficient. The "wing grid" concept was developed by La Roche from Switzerland in 1996 who obtained a patent for his invention (Roche, 1996).

Kravchenco (1996) suggested that modifications in the wingtip can either move the wake vortices away concerning aircraft longitudinal axis or reduce its intensity. Further, he analyzed and concluded that winglets have a higher aerodynamic advantage only up to Mach 1.0, and it may create structural problems due to increased bending moment at the root. Another study by Bagwill et al. (1994) using VLM (vortex lattice method) model investigated winglets for RPV'S (Remotely piloted vehicles) and concluded that winglets increase efficiency for all cases, though the comparison was made only on the wing without winglet for inviscid cases. Smith et al. (2001) have investigated multiple winglets mimicking the wingtip feathers during soaring and found them to help in the diffusion of the wingtip vortices. However such optimization is based mainly on reducing drag due to lift and increasing L/D with little regard to the physical structures that would be necessary to support such a design. Bourdin (2002) in his numerical study found that with fixed span up wash, a winglet produces greater lift-induced drag than downwash. Pfeiffer (2004) developed a method to optimize both induced and profile drag, while the research focused only on winglet orientation and not on size. Results showed only small differences in the root and tip incidences between an induced-drag-only solution and one with profile drag included at high subsonic speeds. Bourdin et al. (2006) investigated the winglets with variable cant angles as an active control surface. They found that even if one or both winglets are adjusted, it affects the multiple moment axes, thus providing a couple of control mechanisms. Takenaka et al. (2008) utilized CFD to investigate the structural stresses associated with winglets and found that if the winglet is not blended into the main wing, there 
will be wave drag at the junction. They investigated a commercial aviation airplane at Mach 0.8 , at a Reynolds number of about $1.2 \times 10^{6}$. Their objective was to optimize the performance based on minimum fuel and Gross Takeoff Weight (GTOW), which are affected by the winglet performance. Their optimization resulted in the design process of blended winglet design with a leading edge aft of the main wing leading edge, and it has been noted that the dominant parameters for the drag reduction are the span length and the cant angle of the winglet. Alexander et al. (2006) studied the wing tip devices at low and high speed using lift and drag component analysis method. They found as per RANS computation good accuracy at high speed and lift. Mann (2008) at Airbus invented a new wing tip which has a downwash tip with $180 \mathrm{deg}$. cant angle and can undergo aeroelastic deformation during flight. Takenaka et al. (2008) while working for the design of winglet for commercial aircraft used multidisciplinary approach by fixing the fuel and take-off distance as the design constraint. CFD with mid-field drag decomposition shows that various winglet defining parameters contribute to the wave, induced and profile drag. Ceron-Munoz et al. (2008) experimented three types of processes, active, passive and adaptive to determine the behavior of three different wingtip devices: delta tip, winglet, and the Hoerner tip. The vortex generation was from three slots on the wing tip. The idea behind this was to study the potential use of adaptive multi-winglets for the reduction of induced drag using different cant angles. They concluded that the Delta tip is very promising in agricultural aircraft with potential benefits in combining both the three vectored Coanda jets and winglet configurations.
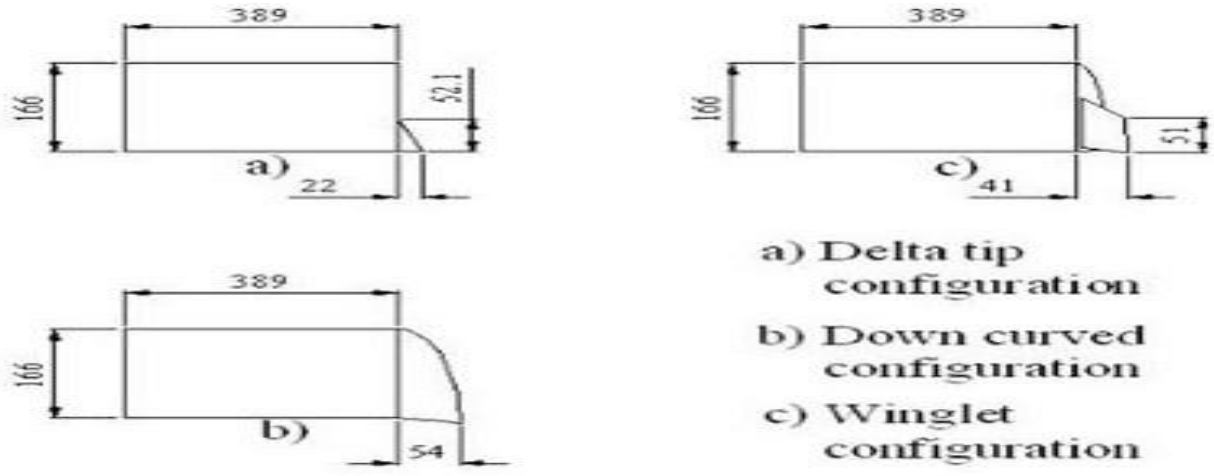

Figure 7. Wing tip configuration used in experiment (Ceron-Munoz et al., 2008)

Jingbai et al. (1995) have conducted experiments on commercial aircraft model to increase the payload and engine performance adopting two different wingtip devices: wingtip sails and sheared wingtips. They found that the wind tunnel result showed both sails and sheared wingtip reduce the induced drag. They 
also showed the effects of sheared wingtips on the lateral and longitudinal aerodynamics. Flight test confirmed all the results predicted by the wind tunnel.

Cosin et al. (2010) through a half model of wing-body investigation at $\mathrm{Re}=4 \times 10^{5}$ tested six different multi winglets. The device showed a $32 \%$ increase in Oswald efficiency factor, resulting in a $7 \%$ increase in aerodynamic efficiency. A $12 \%$ increase in the maximum rate of climb and $7 \%$ increase in maximum range was also obtained. Hicken and Zingg (2010) minimized the induced drag of various non-planar configurations based on Euler equations using an optimization algorithm. They found that elliptical planform is not optimal when side-edge separation is present. Winglet and box-wing when optimized were found to have span efficiencies which agree with lifting line analysis when the entire geometry is accounted for linear analysis. For this reason, (span wise and vertical bound) nonplanar split-tip geometry outperforms both the winglet and box-wing because it can easily maximize the vertical extent at the tip. Inam et al. (2010) experimented with three different wingtip devices namely rectangular, triangular and circular by varying Reynolds number from $0.16-0.25 \times 10^{6}$. They found that drag reduction was in the range of $26.4 \%$ to $30.9 \%$. They also concluded that triangular wingtip design is more promising than the other two. Weierman and Jacob (2010) studied optimization of winglet for use in UAV's compared the various parameters of both Whitcomb and blended winglet with VLM method at low Reynolds numbers. They found than $\mathrm{C}_{\mathrm{L}} / \mathrm{C}_{\mathrm{D}}$ increases for larger radius but the root bending moment is constant and is only influenced by the angle of attack. Also, the best results for $\mathrm{C}_{\mathrm{L}} / \mathrm{C}_{\mathrm{D}}$ are achieved for the lower cant angles. However, since the length is defined to maintain a constant height of 1 meter, the lower the cant angle, the longer the winglet will need to be to reach the necessary height.

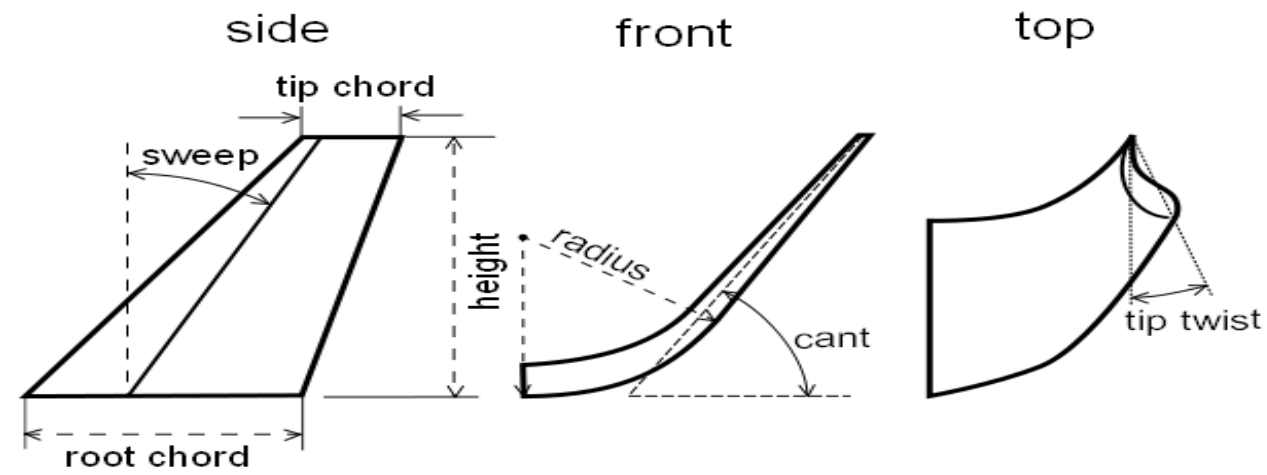

Figure 8. Angles related to wing which affect the aerodynamics function of airplane: Sweep, cant and twist angle (Weierman \& Jacob, 2010) 
$\mathrm{C}_{\mathrm{L}} / \mathrm{C}_{\mathrm{D}} \mid$ max occurs at the maximum radius and the minimum cant angle. The minimum root bending moment, however, lies at the cant angle greater than $70 \mathrm{deg}$. The range and endurance respectively for a blended winglet is $15.61 \%$ and $33.96 \%$ higher than a Whitcomb winglet. CD0 |VLM (Computed through Vortex lattice method) predicts an increase in the range of $10.75 \%$ for the Whitcomb winglet design and a $28.03 \%$ increase in the range for the blended winglet design. The VLM model predicts that the Whitcomb winglet can increase endurance by $28.17 \%$ and the blended winglet can increase it by $71.7 \%$. Using CD0 |WT (Estimated through Wind tunnel), the range is increased by $14.49 \%$ using the Whitcomb winglet and $31.85 \%$ using the optimized blended winglet. So both experiment and simulation agree on these parameters. Christopher and Jeffrey (2011) developed a method to change the incidence angle of wing tip by connecting the desired signal to wing tip rotating mechanism; this is to make the incidence angle of the main wing and wing tip different.

Chang and Hwan (2012) investigated half wing model with aspect ratio 3.2 utilizing three different wingtip configurations namely, square-cut, simple fairing and Whitcomb's. These were visualized at various angles of attack. They found that vortices at a different angle of attack had distinct formation and characteristics. Whitcomb wing tips vortices were found to have more reduction in strength. Another investigation on a half-body model of a trainer aircraft with wing tip blowing, fixed and adaptive multi-winglets was carried out by Ceron-Munoz et al., (2013), they also found that all of them reduce the induced drag, but the maximum reduction occurred with multi-winglets. Giuni and Green (2013) tested the round and square wing tip on a NACA 0012 wing using smoke visualization. They found two different reasons for the vortex fluctuation near wake. One is the rolling-up of vorticity and second is an amalgamation of secondary vortices with primary vortices. An extensive study was performed by Margaris, Marles and Gursul (2010) to examine the effect of continuous blowing from high aspect ratio jet on the tip vortex in the near wake and found that this jet produces a pair of counter-rotating vortices of unequal strength, their interaction with the tip vortex leads to single or multiple-vortex wakes. Rademacher (2014) studied the winglet to retrofit a Dassault Falcon 10 small size business jet using a vortex lattice method solver. He investigated mainly the effect of cant angle, sweep angle and taper ratio and found winglet span and cant angle offer highest gains regarding performance but taper ratio and sweep ratio provide a very little contribution. Rectangular wing NACA0012 with slotted wingtips has been analyzed for low Reynolds number using Fluent. The simulation was done with and without winglet with a decrease in induced drag mostly at an angle of attack of $8^{\circ}$. Such type of wing is specially used in UAV and MAV applications. Jin and Yee (2014) designed a wingtip which they called chipped wingtip. Their main purpose was to reduce the vortex generation 
behind the wing. Numerical simulation using incompressible Navier-Stokes equation was used to see the effect of that wing shape. They found that vortices were more dissipative than the main wingtip and resulting vortices can reduce the strength of primary vortex at far field.

\section{Bird feather tip for drag reduction research}

One of the first complete books on this subject was written by Otto Lilienthal, Lilienthal (1889) and then by Magnan (1980), which shows a linear trend to relate aviation problems with bird flight. Now after decades due to the requirement of UAV's and MAV's this natural inspiration is being looked at with new enthusiasm.

Graham (1932) was the first who made extensive studies on bird feather tips proposing possible relation between feather slot and drag. He also pointed out the major structural differences between soaring birds over land and sea and suggested that formation of slotted feather tip with vertical feather is due to the force of air, as there is no muscle at the tip which can contribute to the said task. As per Hummel (1980) Max Munk in 1919 has shown in a French paper that for a planar wing, induced drag cannot be less than:

$$
C_{D_{\text {imin }}}=\frac{L^{2}}{\frac{1 \rho V^{2} \pi b}{2}}
$$

Newman (1958) revealed that a plane lifting system of tandem wings could not reduce induced drag; on the contrary, the lifting system must be non-planar to achieve a reduction in induced drag. Hummel (1980) proved using experimental data that induced drag for planar wings is more than that predicted by Munk. 


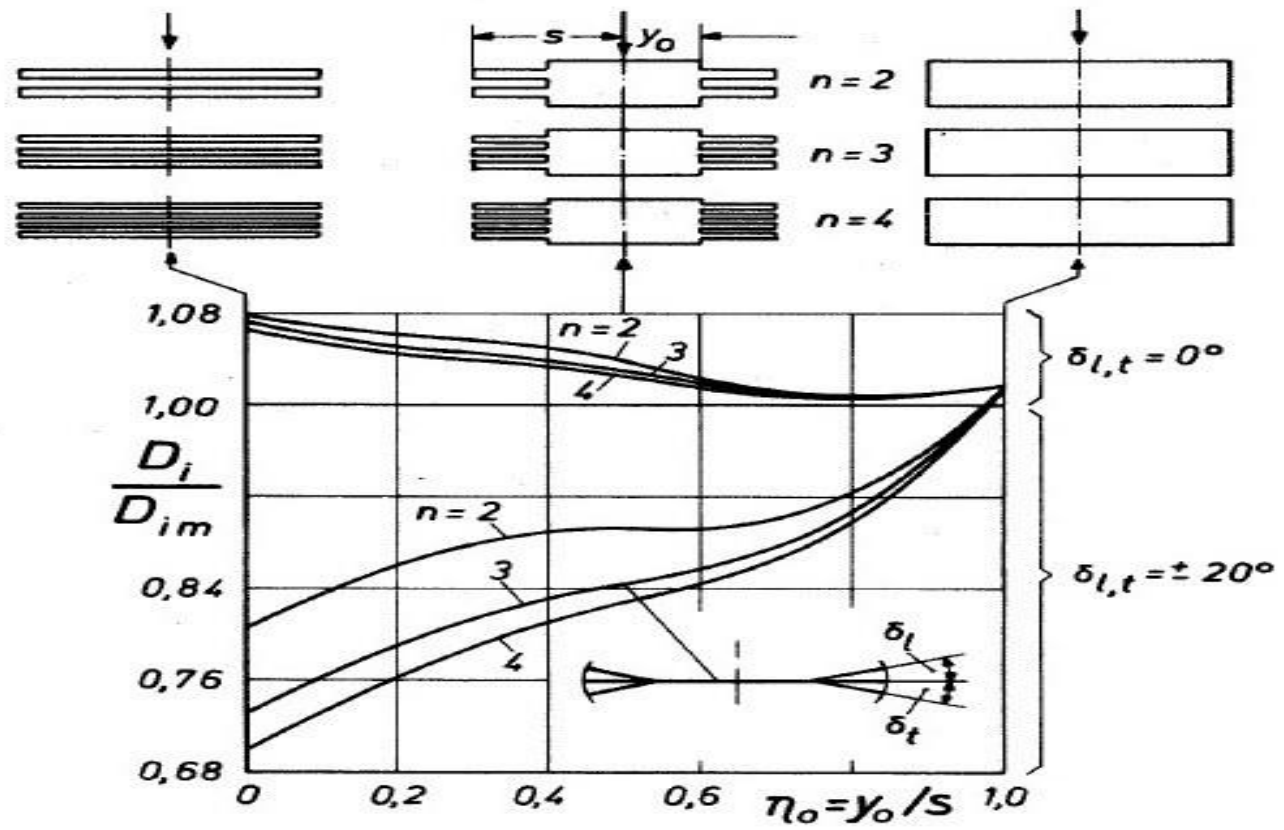

Figure 9. Experimental setup with wingtips ranging $\mathrm{n}=2$ to 4 and graph by (Hummel, 1980)

Bird wings are considered as nonplanar, and a basic theory of nonplanar systems is given by Cone (1962) to determine minimum induced drag and lift that can be expressed regarding aspect ratio and vortices distribution.Tucker (1987) attempted to study the aerodynamics of bird wings with two different birds; the Falcon and the Vulture, which freely glide in a wind tunnel by decreasing their wing span. Due to this the induced drag increases and probably increased $\mathrm{C}_{\mathrm{d}}$ for the inner parts of the wing because of an unusual property of bird-like aerofoil sections: wings with such section have minimum values of $\mathrm{C}_{\mathrm{d}, \mathrm{pr}}$ (profile drag coefficient) at $\mathrm{C}_{1}$ near 1 , while the conventional wings have minimum $\mathrm{C}_{\mathrm{d}, \mathrm{pr}}$ at $\mathrm{C}_{1}$ near 0 . The aerodynamic performance of real birds was studied by Pennycuick et al. (1988) who used a frozen waterfowl in a wind tunnel to estimate the drag coefficient at Reynolds number of $1.45 \times 10^{5}-4.62 \times 10^{5}$ but was related to estimate the body drag of large birds with well streamlined bodies. Tucker (1993) used the four primary feather wing tips made from a Harris Hawk and the Clark Y tip which was unslotted and made of balsa wood. With this, the total drag reduction with the feathered tip was $12 \%$ less than that of a hypothetical wing with the same lift and span. This value he found is consistent with the wing theory predictions on drag reduction from winglets. 


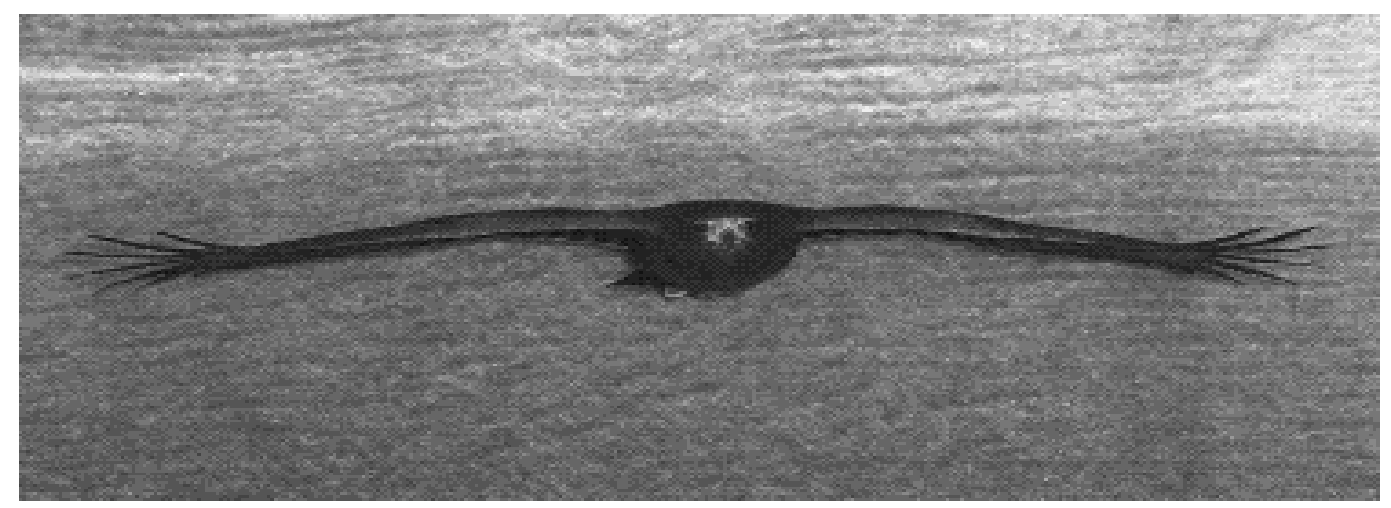

Figure 10. Vertical separation between the feathers in the slotted wing tips(Tucker, 1993)

Tucker (1995) conducted experiments on a Harris' hawk which glided freely inside a wind tunnel. The minimum drag was measured before and after removing the slots by clipping the tip feathers. The hawk with slots (unclipped) had $70-90 \%$ of the drag compared to clipped wings. For a wingspan of $0.8 \mathrm{~m}$, the slotted wing tip has induced drag factor of 0.56 , compared with the value of 1.10 assumed for the clipped hawk.

Withers (1981) shows that bird wings encounter low drag with less maximum lift coefficient and high drag with high lift coefficient. He found through pressure-distribution data that the air flow pattern over bird wing is consistent with the aerodynamic theory for airplane wings at low Reynolds number. In general, the primary feathers of several birds bend upwards and separate vertically to form a slotted wing tip which is responsible for the reduction in induced drag.

Crandell and Tobalske (2011) have studied the tip-reversal phenomena in slow flying birds and proposed two hypotheses. First, this tip-reversal is only related to a reduction of drag. Secondly, it can provide aerodynamic forces. For this, they used rock dove wings and spun it in vivo Reynolds numbers for simulation. They found by comparing with a $3 \mathrm{D}$ wing that the wing in the upstroke posture is capable of producing substantial aerodynamic forces. At in vivo angles of attack $\left(66^{\circ}\right.$ at mid-upstroke, $46^{\circ}$ at the mid-down stroke), the upstroke wings, averaged for three birds, produced a lift-to-drag ratio of 0.91 , and the down stroke wings produced a lift-to-drag ratio of 3.33. Peak lift-to-drag ratio was 2.5 for upstroke and 6.3 for down stroke. During each half-stroke total force production produces a force that supports $115 \%$ of body weight, and during upstroke force is generated at $36 \%$ of body weight. According to Fluck and 
Crawford (2014), an increase in wing efficiency by splitting the wing tip like birds feather wingtip is possible and found that the best performance can be achieved through spreading the wing tip like the spreading of feathers over a large angle of the wing planform. Hua et al. (2014) have shown that bionic wing aerodynamics performance is superior to the conventional airfoil wing. Eder et al. (2015), estimated the induced drag factor of free flying White Storks by calculating bird speed and wing loading and aspect ratio. The induced drag factor ranges from 0.7 to 0.96 at lift coefficients of 1.2-1.6.

Sachs and Moelyadi (2006) concluded that sweep inside the wing tip provides a significant contribution to yawing moment and stability. The aerodynamic forces and pressure distribution were measured by revolving dried pigeon wing and a flat card replica. They were tested at Reynolds numbers up to 108,000 which is typical for slow-flying pigeons. The pigeon wing out-performed the flat card replica, reaching lift coefficient 1.64 compared to 1.44, Both real and model wings achieved much higher maximum lift coefficients, and at much higher geometric angles of attack, than would be expected from wings tested in a wind tunnel simulating translating flight (Usherwood, 2009). Guerrero, Maestro, and Bottaro (2012) found that due to drag breakdown the lift- induced drag can be $40 \%$ of total drag at cruise and during take-off $80-90 \%$. However, according to Anderson (2001), the induced drag at cruise is about $25 \%$ of the total and during take-off can be more than $60 \%$.

The physical configuration of bird's feather in different phases and then a comparison between bird feather wingtip and airplane wingtips are shown below.

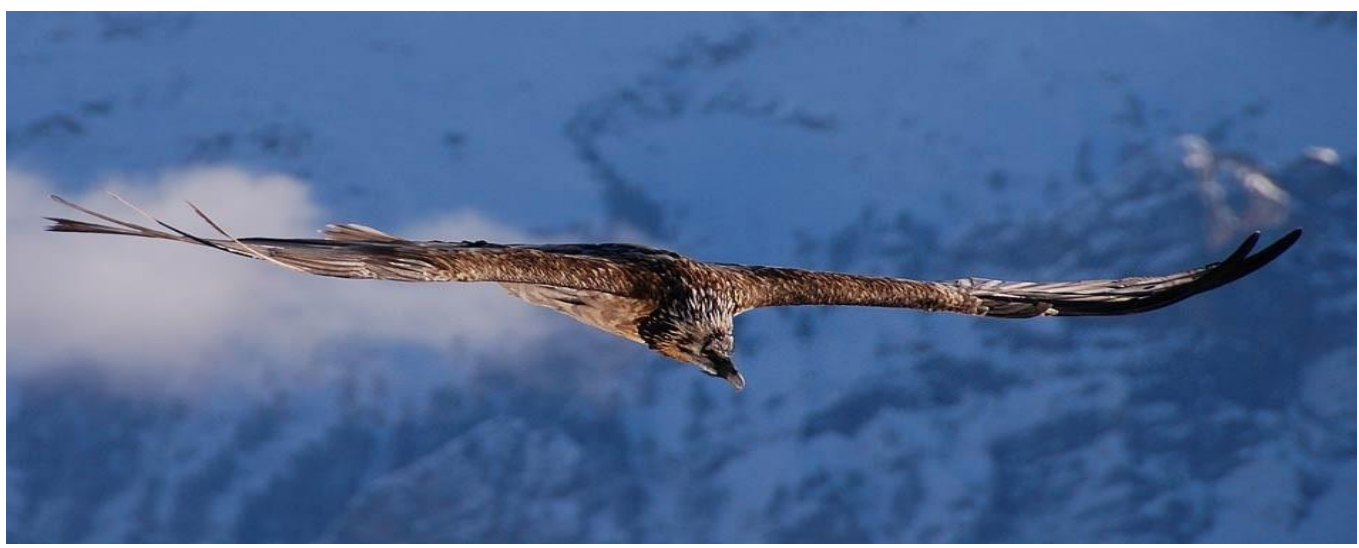

Figure 11. Vulture during cruise (http://dinoanimals.com) 

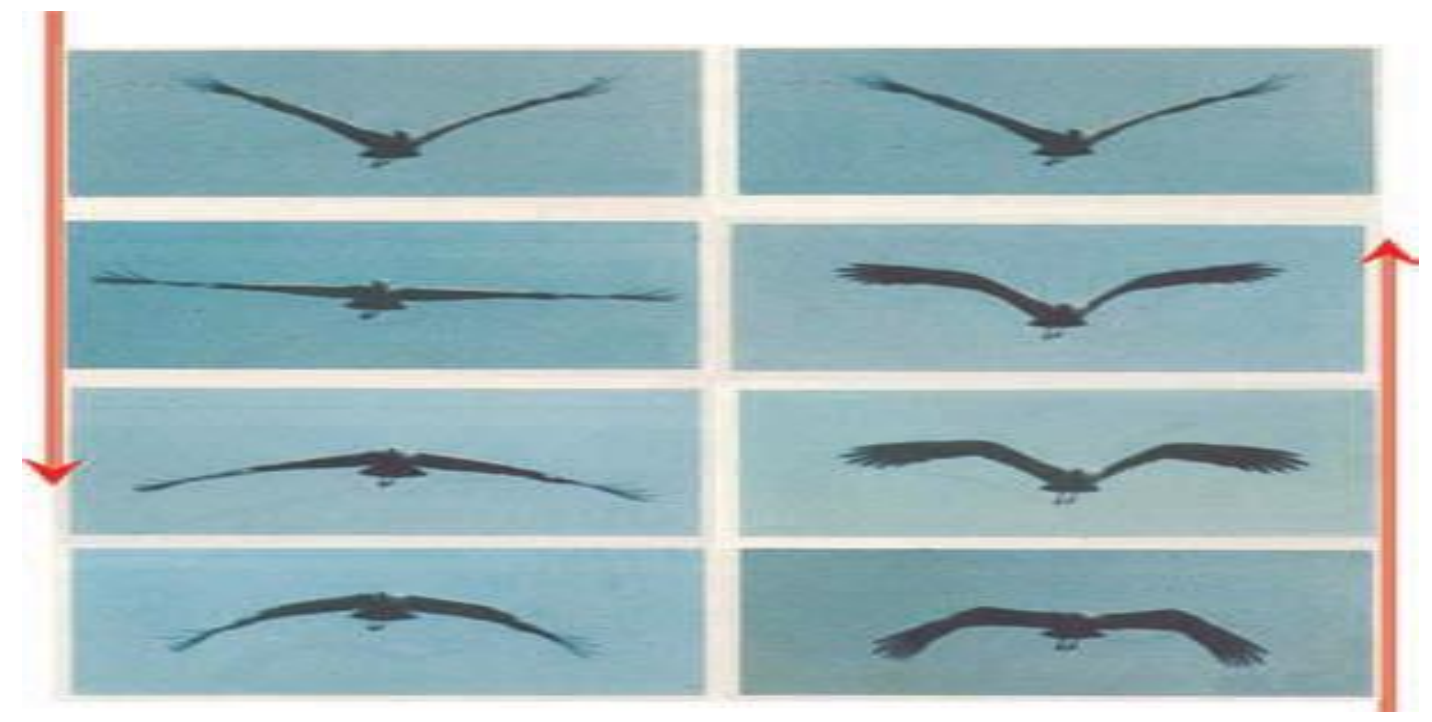

Figure 12. Wing motion of stork with landing and take-off (Shreyas et al., 2011)

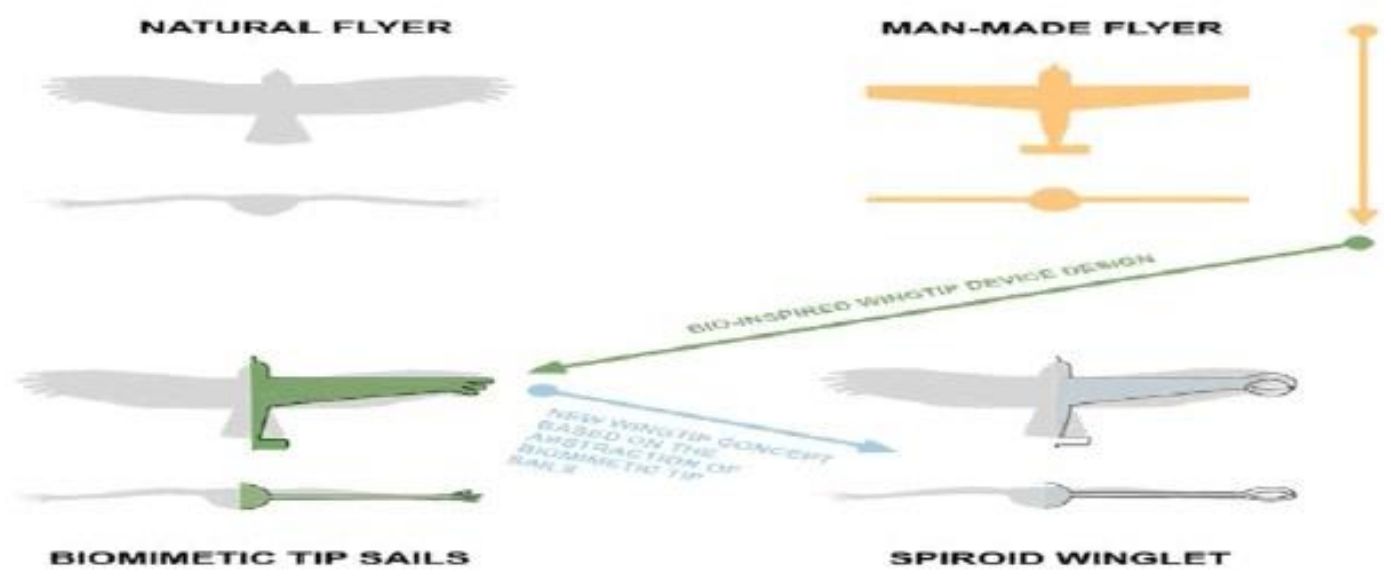

Figure 13. The premises of spiroid winglet has been compared with natural flyer (Raj \& Thomas, 2015) 

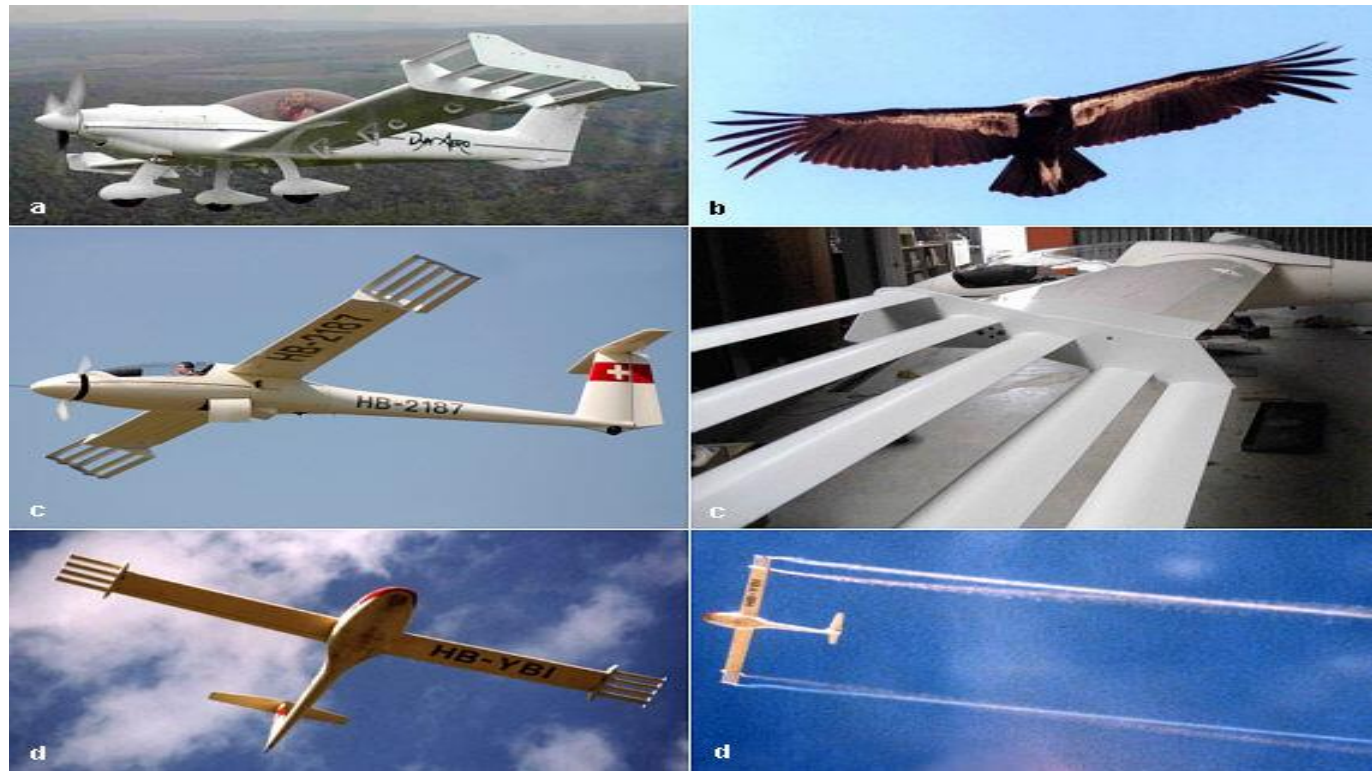

Figure 14. . A comparison of natural flyer with 'wing grid' configuration (http://www.rcgroups.com)

The common winglet used today is the blended winglet, but there are some other winglet designs prevalent in the aerospace industry. All have their own pros and cons and optimizing any single winglet for all purposes seems very difficult. Given below are the photographs of common winglets:- 


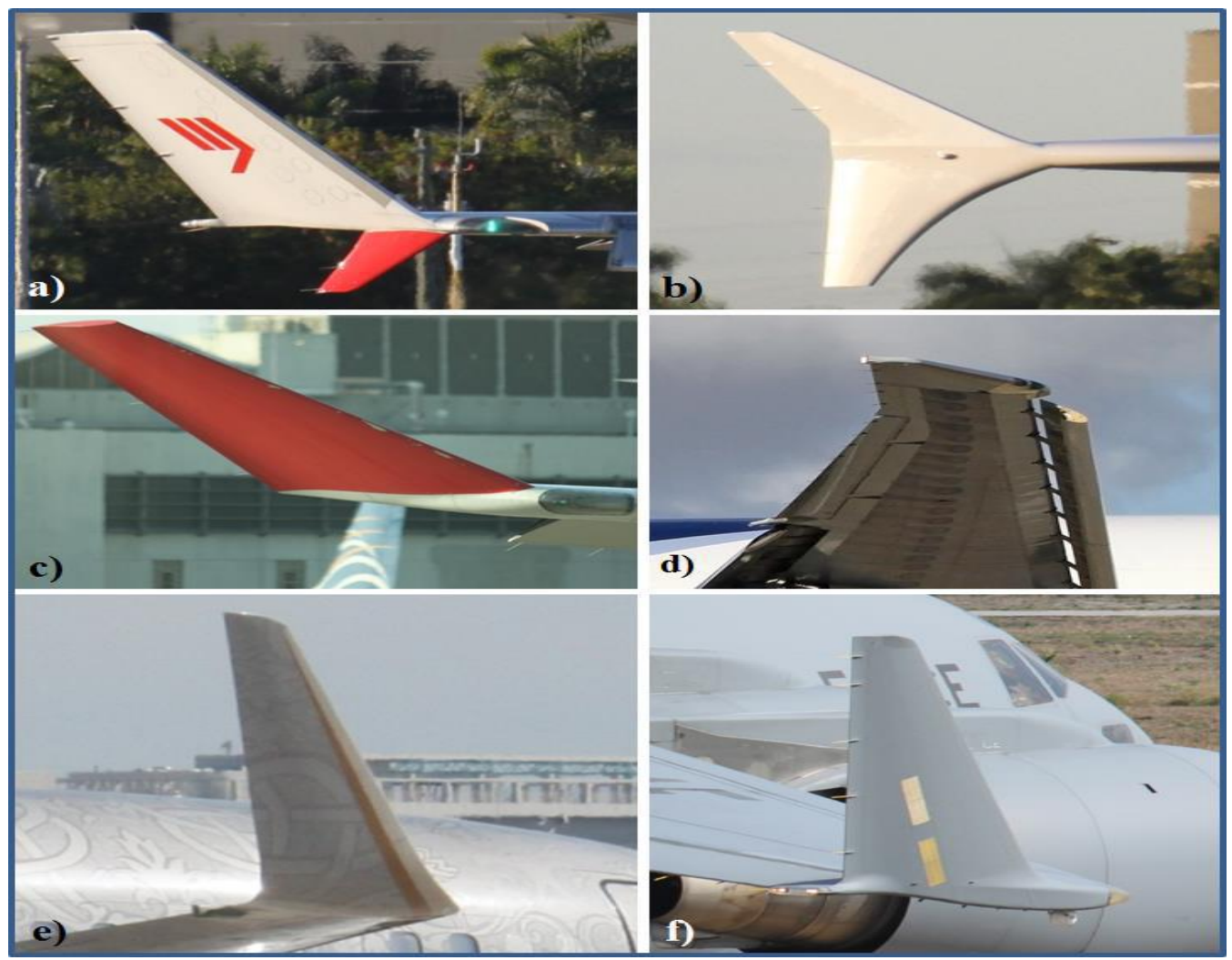

Figure 15. Selected Winglet Configurations. a) Whitcomb Winglet (McDonnellDouglas MD-11), b) Wingtip Fence (Airbus A380), c) Canted Winglet (Airbus A330), d) Raked Wingtip (Boeing 777F), e) Blended Winglet (Boeing 737), f) Simple Winglet (Boeing C-17A Globemaste III) Pictures by (Rademacher, 2015)

Despite such major improvements in winglet design, there are still some areas to be explored in future (Gudmundsson, 2014; McLean, 2005):

1. Drag: Winglets increase profile drag due to the additional wetted area and possible interference flow between wing and winglet.

2. Weight: The empty weight of the aircraft is increased due to the winglet itself and the installation of attachment fittings.

3. Structural changes: The attachment of winglets and the increase in wing bending moments may require substantial wing structural reinforcements. 
4. Flutter: The higher weight at the tip from the winglet as well as structural modifications can have a negative impact on the flutter and fatigue characteristics of the aircraft by reducing the natural frequency of the wing.

5. Stability: The winglet cannot effectively increase the dihedral effect of the wing, therefore changing the stability of the aircraft. Also, a vertical winglet adds additional side area to the aircraft upon which a crosswind during landing can act, potentially decreasing the maximum crosswind limit of the aircraft.

\section{Conclusion}

Past research regarding analysis, simulation, and experiment for biomimetic and conventional wingtips have been reviewed. It can be seen that lift-induced drag and its effect has been handled with three approaches. First is very direct in which new wingtip designs were proposed and gradually modified for more efficiency. The second method is indirect which first analyze the bird wingtip effect on induced drag through simulation and experiment. Some have used original birds for this method, and some have used their models for the same. At last some questions have been posed which still need to be explored such as an increase in profile drag due to a new design, increased structural weight, modification in a wing to accommodate new tips, change in flutter and fatigue characteristic and the stability of the airplane. Birds can move their feathers in numerous ways to provide aerodynamic control, which involves the role of sweep of feather, separated feather tip and aeroelasticity (flexibility) of feather, all such factors can be a topic of future research considering applications like UAV and MAV, general aviation as well as large aircraft with categorization of speed, range shape, and size.

Research has been done to investigate the aerodynamic behavior of various shapes of bird feather tip, assuming them fixed or rigid airfoil at different angles of attack. Moreover, both real bird feather and conventional airfoils were used to investigate the same. Although work has been done with rigid wingtip as a prototype of birds' wing tip, they do not represent the flexibility of bird feathers. This important aspect is also lacking from the literature which is key to birds' flight. The generation of vortices behind the bird wingtips is also an area which did not attract attention so far as has been done for the fixed wings in aircraft. The six component balance data which contain valuable information has not been used for wings with rigid and flexible tips, hence a pool of data is unavailable in the form of Yawing, Pitching \& rolling moment and forces. When it comes to stability and control considering bird wing tips, only the yawing moment of bird feather found some attention, but very few studied the effect of the pitching and rolling moments. The mathematical model available for an airplane in the form of lifting line theory is not yet developed for bird flight except what has been done by Fluck (2014). 
Study of bird's slotted wing tips at low speed, and low range can be studied for application in UAVs or MAVs during object oriented perching and other targets. The special shape of spiroid has predicted an increase in aerodynamic performance of the aircraft by increasing fuel efficiency and dispersing the vortices in short time span providing frequent take-off, hence further research considering these benefits can be adopted for UAVs and MAVs. Computational techniques need urgent attention to include elastic considerations as simulations are very limited.

References 
Anderson, J. D. (2001). The fundamental of aerodynamics. New York, NY: McGraw Hill.

Bagwill, T. L., \& Selberg, B. P. (1994). An Inviscid aerodynamic investigation of Wing/ Winglet geometries for RPV Applications. SAE technical paper, 941144. (Aerospace Atlantic Conference and Exposition, Dayton.)

Barber, M. R., Selegan, D., Montoya, L., Jacobs, P., Flechner, S., \& Sims, R. W.M. (1981). KC-135 Winglet Program Review. Symposium Dryden Flight Research Centre Edwards: NASA Ames Research Centre - Dryden Flight Research Facility.

Bourdin, P., Gatto, A., \& Friswell, M. I. (2006). The application of variable cant angle winglets for morphing aircraft control. 24th Applied Aerodynamics Conference, AIAA 2006-3660.

Bourdin, P. (2002). Numerical predictions of wing-tip effects on lift-induced drag. ICAS $23^{\text {rd }}$ congress, 2002, 223.1-223.10.

Buscher, A., Radespiel, R., \& Streit, T. (2006). Modelling and design of wing tip devices at various flight conditions using a databased aerodynamic prediction tool. Aerospace science and technology, 10, 668-678.

Bushnell, D. M., \& Tuttle, M. H. (1979). Survey and Bibliography on attainment of laminar flow control in air using pressure gradient and suction. NASA Report-1035.

Ceron-Munoz, H.D., Cosin, R., Coimbra, R.F.F., Correa, L.G.N., \& Catalano, F.M. (2013). Experimental investigation of wing-tip devices on the reduction of induced drag. Journal of Aircraft, 50, 2-441.

Cerón-muñoz, H. D., Catalano, F. M. \& Coimbra, R. F. (2008). Passive, active and adaptive systems for wing vortex drag reduction. Proceedings of the 11th Brazilian Congress of Thermal Sciences and Engineering society of mechanical sciences and engineering (ICAS 2008).

Chang, J., \& Hwan, S. (2012). Visualization and PIV study of wing-tip vortices for three different tip configurations. Aerospace Science and Technology, 16(1), 40-46.

Cone, C. D. (1962). The theory of induced lift and minimum induced drag of nonplanar lifting systems. NASA TR R-139. 
Conley, N. (1980). Winglet toe-out optimization for the Gates Learjet Longhorn wing. Journal of Aircraft, 17, 851-855.

Cosin, R., Catalano, F. M., Correa L.G.N., \& Entz, R.M.U. (2010). Aerodynamic analysis of multi-winglets for low-speed aircraft. In proceedings of 27 th International Congress of the Aeronautical Sciences (ICAS 2010).

Craes, P. J. H. (2014). F.W Lanchester and the great divide. Journal of Aeronautical History, 2, 55-105.

Crandell, K. E., \& Tobalske, B. W. (2011). Aerodynamics of tip-reversal upstroke in a revolving pigeon wing. Journal of Experimental Biology, 1(214), 1867-73.

Cristopher, A.K., \& Jeffrey, P.S. (2011). United states patent, US 8083185 B2.

Degen, M., Johnson, A. R. \& Thompson, W. E. (1957). Aerodynamic characteristics of ring wings and ringwing-body combinations. WADC Report, TP 46-442.

Dengbin, T., Qian, J., \& Mingquan, S. (1994). Applications and developments of Wing-tip devices to Reduce Drag. Journal of Nanjing University of Aeronautics and Astronautics, 1994-01.

Eder, H., Fiedler, W., \& Neuhäuser, M. (2015). Evaluation of aerodynamic parameters from infrared laser tracking of free-gliding white storks. Journal of Ornithology, 156, 667-677.

Fluck, M,. \& Crawford, C. (2014). Lifting line model to investigate the influence of tip feathers on wing performance. Bioinspiration and Biomimetic [Bioinspired Biomim], 9(4), 046017.

Giuni, M., \& Green, R.B. (2013). Vortex formation on squared and rounded tip. Aerospace science and technology, 29, 191-199.

Graham, R.R. (1932). Safety devices in wings of birds. Journal royal Aerospace Society, 36, 24-58.

Gratzer, L. B. (1992). Spiroid-tipped wing. United states patent, 5102068.

Gratzer, L. B. (1994). Blended winglet. United states patent, 5348253. 
Gudmundsson, S. (2014). General Aviation Aircraft Design: Applied Methods and Procedures (1st ed.). Butterworth-Heinemann, New York.

Guerrero, J. E., Maestro, D., \& Bottaro, A. (2012). Biomimetic spiroid winglets for lift and drag control. Comptes Rendus Mecanique, 340(1), 67-80.

Hackett, J. E. (1980). Vortex diffuser. US Patent, 4,190,219.

Hackett, J. E. (1980). Vortex drag reduction by aft-mounted diffusing vanes. ICAS paper, $80,13.4$.

Henderson, W. P., \& Holmes, B. J. (1989). Induced drag-historical perspective. SAE paper-2341.

Heyson, H. H., Riebe, G.D., \& Fulton, C.L. (1977). Theoretical parametric study of the relative advantages of winglets and wing-tip extension. NASA-TP-1020, L-11679.

Hicken, J. E., \& Zingg, D. W. (2010). Induced-drag minimization of nonplanar geometries based on the Euler equations. AIAA Journal, 48(11), 2564-2575.

Hua, X., Ji, Z., Lei, M., \& He, Z. (2014). The bionic wing with winglet in near space aerodynamic analysis. Applied mechanics and materials, 644650, 1939-1942.

Hummel, D. (1980). The aerodynamics characteristics of slotted wingtips in soaring birds. Proceedings of the $17^{\text {th }}$ international ornithological congress, Berlin.

Inam, M.I., Mashud, M., Nahian, A., \& Selim, S.M.S. (2010). Induced drag reduction for modern aircraft without increasing the span of the wing by using winglet. International journal of mechanical and mechatronics, 10, 49-53.

Jin, J.H. S., \& Yee, K. (2014). Numerical simulation of trailed vortex alleviation through chipped wingtip shapes. Journal of Mechanical Science and Technology, 28(9), 3605-3615.

Jingbai, L. (1995). Wind tunnel investigation of drag reduction by wing-tip mounted devices on an aircraft. Journal of Nanjing University of Aeronautics and Aetronautics, 1995- 01. 
Jones, R. T., \& Lasinski, T. A. (1980). Effect of Winglets on the Induced Drag of Ideal Wing Shapes. NASA TM-81230.

Keisuke, A. (1985). Theoretical Considerations in the Aerodynamic Effectiveness of Winglets. Journal of Aircraft, 22, 635-637.

Kravchenco, S. A. (1996). The application of the wingtip lifting surfaces for practical aerodynamic. ICAS, 1338-1349.

Kroo, I., McMasters, J., \& Smith, S. C. (1996). Highly non-planar lifting systems. NASA CP 10184 Part 1, 331-370.

Kuhlman, J. M., Liaw, P., \& Cerney, M. J. (1988). Theoretical/Numerical Study of Feasibility of Use of Winglets on Low Aspect Ratio Wings at Subsonic and Transonic Mach Numbers to Reduce Drag. NASA CR4174.

Roche, L. U., \& Palffy, S. (1996). Wing-grid, a novel device for reduction of induced drag on wings. ICAS $20^{\text {th }}$ Congress, 2, 2303-2309.

Lilienthal, O. (2001). Bird Flight as the Basis of Aviation. Longmans green and company, New York.

Lyapunov, S. V. (1993). Nonplanar wings with a minimum induced drag. Fluid dynamics, 28, 238-243.

Magnan, A. (1980). Bird Flight and Airplane Flight. NASA TM-75777.

Mann, A. (2008). Wing tip devices. United states patent, 8342456 B2.

Margaris, P., Marles, D., \& Gursul, I. (2007). Experiments on Interaction of a Jet with a Trailing Vortex. 45th AIAA Aerospace Sciences Meeting and Exhibit, Aerospace Sciences Meetings, 1123, Reno, Nevada.

McLean, D. (2005). Wingtip Devices. 'What They Do And How They Do It. Boeing Performance and Flight Operations Engineering Conference, Article 4.

Munk, M.M. (1921).The Minimum Induced Drag of Aerofoils. NACA Report No. 121.

NASA's First A - Aeronautics from 1958 to 2008, The NASA History Series NASA SP-2012-4412. 
Newman, B.G. (1958). Soaring and gliding flight of the black vulture. Journal of experimental biology, 35, 280-285.

Norberg, U (1990). Vertebrate Flight- Mechanics, Physiology, Morphology, Ecology and Evolution. Springer-Verlag Berlin Heidelberg, Berlin.

Pennycuick, C., Obrecht, H. H., \& Fuller, M. R. (1988). Empirical estimates of body drag of large waterfowl and raptors. Journal of Experimental Biology, 135(1), 253-264.

Pfeiffer, N. (2004). Numerical Winglet Optimization. 42nd AIAA Aerospace Sciences Meeting and Exhibit, Aerospace Sciences Meetings, AIAA 2004-0213.

Rademacher, P. R. (2014). Winglet Performance Evaluation through the Vortex Lattice Method. Dissertations and Theses Paper 178. Embry-Riddle Aeronautical University, Daytona Beach, Florida.

Raj, W. G., \& Thomas T.A. (2015). Design and analysis of spiroid winglet. International Journal of Innovative Research in Science, Engineering and Technology, 4, 1139-1147.

Rokhsaz, K. (1993). A brief survey of wing tip devices for drag reduction. $S A E$ paper, 102-1, 932574

Sachs, G., Moelyadi., \& Mochammad, A. (2006). Effect of slotted wing tips on yawing moment characteristics. Journal of Theoretical Biology, 239(1), 93-100.

Shreyas, J.V., Devranjan, S. \& Sreenivas, K.R. (2011). Aerodynamics of Bird and Insect Flight. Journal of the Indian Institute of Science, 91(1), 415427.

Smith, M. J., Komerath, N., Ames, R., \& Wong, O. (2001). Performance Analysis of a Wing with Multiple Winglets. AIAA $19^{\text {th }}$ applied aerodynamics conference, Anaheim, AIAA-2407.

Spillman, J. J. (1978). The use of wing tip sails to reduce vortex drag. The Aeronaut Journal, 82, 387-395.

Spillman, J. J. (1987). Wing tip sails: progress to date and future developments. The Aeronautical Journal, 91,445-453. 
Takenaka, K., \& Hatanaka, K. (2008). Multi-disciplinary Design Exploration for a Winglet. Journal of Aircraft, 45, 1601-1611.

Tucker, V. A. (1987). Gliding birds: the effect of variable wing span. Journal of Experimental Biology, 133(1), 33-58.

Tucker, V. A. (1993). Gliding birds: reduction of induced drag by wing tip slots between the primary feathers. The Journal of experimental biology, $180(1), 285-310$.

Tucker, V. A. (1995). Drag reduction by wing tip slots in a gliding Harris' hawk, Parabuteounicinctus.The Journal of experimental biology, 198(3), 775-781.

Usherwood, J. R. (2009). The aerodynamic forces and pressure distribution of a revolving pigeon wing. Experiments in Fluids, 46(5), 991-1003.

Webber, G. W., \& Dansby, T. (1983). Wing tip devices for energy conversion and other purposes. Can. Aeronaut. Space Journal, 29(2), 105-120.

Weierman, J., \& Jacob, J. (2010). Winglet design and optimization for UAVs. 28th AIAA Applied Aerodynamics Conference, AIAA-4224.

Whitcomb, R. T (1976). A Design Approach and Selected Wing-Tunnel Result at High Subsonic Speed for Wing-Tip Mounted Winglets. NASA TN D8260 .

Withers, P. C. (1981). An aerodynamic analysis of bird wings as fixed aerofoils. Journal of Experimental Biology, 90(1), 143-162.

Yates, J. E., \& Donaldson, C.P. (1986). A fundamental study of drag and an assessment of conventional drag drag-due-to-lift reduction devices. Contractor NASA 18065.

Zimmer, H. (1987). The aerodynamic optimization of wings at subsonic speeds and the influence of wingtip design. NASA-TM- 8853 . 